\title{
Collaborative Project-Based Learning via Augmented Reality on m-Learning Model to Enhance Basic ASEAN Community Skills for Thai and the Lao PDR Students
}

\author{
Wichai Trilek, Pullop Piriyasurawong, and Namon Jeerungsuwan
}

\begin{abstract}
The purpose of the research study were to design and evaluate a collaborative project-based Learning via augmented reality on m-learning model to enhance basic ASEAN community skills for Thai students and The Lao People's Democratic Republic students. The research results indicated that: 1 . the model which has been developed consists of six components and five processes. The six components of the model were: 1) Definition of Project Objective, 2) Intelligent Support Engine, 3) Project Activities, 4) People Involved, 5) Evaluation system, and 6) Augmented Reality Technology. The activities include with five processes were: 1) activity preparation, 2) project operation, 3) sharing and collaborative learning between Thai students and The Lao People's Democratic Republic students by doing project, 4) project presentation, and 5) evaluation. 2) Evaluation of the model by five experts was evaluated at highest appropriateness, $(\bar{X}=4.96)$, (S.D.= 0.05).
\end{abstract}

Index Terms-Collaborative learning, m-learning, project-based learning, augmented reality, ASEAN community skill.

\section{INTRODUCTION}

By the year 2015, the ASEAN countries will combine as one community under the motto "One Vision, One Identity, and One Community". This leads to the changes and collaborations in various aspects especially society, economy, and politics. Office of the Basic Education of Thailand then focus ASEAN-driven learning by building awareness and enhancing knowledge of understanding as a part of ASEAN community. They have defined four basis for Thai students towards ASEAN community; 1). Be able to communicate at least two languages (English and at least one another neighbouring language), 2). Be able to use information technology efficiently and creatively, 3). Have an ability to solve problem with peaceful means, 4). Be able to work and live with others harmoniously [1].

The four basis are the desirable $21^{\text {st }}$ Century Skills of learners. The previous education reformation mainly focuses on the education structure but the quality of education which is more important has not been concerned enough. This causes the lack of thinking, analyzing, and synthesizing capability to solve problems in Thai youth. Including the

Manuscript received February 30, 2015; revised June 23, 2015.

The authors are with the Department of Information and Communication Technology for Education, Faculty of Technical Education, King Mongkut's University of Technology North Bangkok. Bangkok, 10800, Thailand (e-mail: wichaitr@yahoo.com, palloppi@gmail.com, namon2015@gmail.com). fluent in English in which the main communication language of ASEAN community, it is also poorer than other ASEAN countries for Thai youth [2]. The best learning occurs when learners do something in person (Learning by doing). The sharing learning analogous with project-based learning is a kind of learning management according to Constructionism method which relies on information communication technology as a tool in gathering information and knowledge then presenting and demonstrating results through various media systems. Those media moreover be able to create an interactive system environment makes the new learning era success. The learners' behaviour has been changed from being inactive to an active one. They are more quests to get information and knowledge [3]. The project-based learning, learners themselves are the one who construct their knowledge and work as a team to search for information as well as preparing information for doing presentation. Learners are the centre of learning because they perform thinking, doing, making decision, and solving problems by themselves with teachers' support in giving guidance and also learning together with the learners. Hence, the learning environment is an absolutely collaborative learning resulted in the greater academic achievement [4]. The collaborative learning is then the learning medium focused the learner centre model complying with National Education Act B.E. 2542.

The information and communication technology of the $21^{\text {st }}$ century has become an important social change progressively and importantly in every dimension especially computer technology and telecommunication system that can reach the world-connected system. For the educational system, m-learning education using mobiles and handheld computers is more important as a channel of knowledge transmission and an innovation of studying [5]. This creates a ubiquitous learning environment of Collaborative Learning for students with both virtual and actual learning and with both synchronous and asynchronous communication. Thus, the preparation of Thai's youth learning to ASEAN community can use an online social network in order to communicate and learning together among ASEAN's schools. This will bridge the instructors and the students together through wireless network to eliminate place and time constraints of education. It also can be applied with augmented reality technology which integrates virtual world with real world. The three-dimensional virtual images are displayed on the computer screen, smart phone, or other display devices real time. The use of augmented reality technology study found that it has outstanding advantages over other learning media. 
It makes greater interests of the content, better learning pleasant, and better learning outcome [6]. Thus, this learning model to enhance Thai students' skills can use social network in communicating and learning collaboratively. The project will be a basis in linking schools in Thailand with other schools in other ASEAN countries.

The researcher interests in developing a collaborative project-based learning via augmented reality on m-learning model to enhance basic ASEAN community skills for Thai students and The Lao People's Democratic Republic students since Lao PDR is one of the ASEAN countries that share the common border with Thailand. We are brotherhood countries with similarities of language, culture, and traditions. Therefore, it is convenient and possible to perform the experiment in terms of time zone, location, budget, and coordination. The research outcome is an important guide to develop the collaborative learning between Thailand and other neighbouring ASEAN countries in the future.

\section{OBJECTIVE OF THE STUDY}

To design and evaluate a Collaborative Project-Based Learning via Augmented Reality on m-learning Model to Enhance Basic ASEAN Community Skills for Thai Students and The Lao People's Democratic Republic Students.

\section{RESEARCH PROCEDURE}

The research methods have been categorized into three phases as follows:

Phase 1: To study a model. Its processes are as follows: 1) Explore the problems and requirements to enhance basic ASEAN community skill for Thai students 2) Study, analyze, and synthesize the related research studies and papers 3) In-depth Interview five experts

Phase 2: To design a model, using the synthesized data from the Phase 1 research as a conceptual framework. This phase emphasizes on the relationships among components, processes, and a systematic approach according to ADDIE model.

Phase 3: To evaluate a model by 5 experts specialized in collaborative project-based learning, augmented reality, m-learning, ASEAN community, and information communication and technology education.

\section{RESULTS}

\section{A. The Study and Design Result of a Collaborative Project-Based Learning via Augmented Reality on m-Learning Model}

The Collaborative Project-Based Learning via Augmented Reality on m-learning Study results shows that the model should consist of six components and five processes.

Those six model components are as follows:

1) The Definition of Project Objective: to enhance basic ASEAN community skills for Thai students and The Lao People's Democratic Republic students via ICT and augmented reality technology. The Ministry of Education has defined the Thai's children characteristics in ASEAN community that 1) be able to communicate at least two languages (English and at least one another neighbouring language), 2) be able to use information technology efficiently and creatively, 3) have an ability to solve problem with peaceful means, 4) be able to work and live with others harmoniously.

2) Intelligent Support Engine: Those are 1) website supports collaborative project-based learning, 2) wireless network technology, 3) learning management system software (mLMS), 4) various additional learning materials to support instructions via mobile screens or handheld devices, 5) part of interactive learning via handheld's keyboard and screen, and 6) other communication devices

3) Project Activities: are the content under the students' interests such as travelling project, cultural advisory project, language teaching project, and national cuisine project.

4) People Involved: Those are 1) instructors, 2) students, 3) executives, 4) parents, 5) specialists, and 6) coordinators from both Thailand and Lao PDR.

5) Evaluation System: Those are 1) examination storage system, 2) statistical reporting system, 3) assessment of ASEAN's basic skills, and 4) evaluation from project's outcome.

6) Augmented Reality Technology: is the integrated technology between virtual system technology and image technology to create virtual image. These virtual objects and information aggregated by teachers, students and experts compile as a database of the project's website including 3D objects, VIDEO, AUDIO and other components. The background image is a component which derives from the real environment and real time via software and connected devices such as webcams, computers and other equipment. Virtual images are displayed on the computer screen, mobile phone, projector, or other display devices according to the design of learning activities. The processed images interact promptly with students as three-dimensional images, animations, or sound effects making more realistic perception by students.

Those five processes are as follows:

1) Activity Preparation Process: consists of 1) the agreement and action plan creation of the cooperation projects between Bodin decha (sing singhaseni) school in Bangkok Thailand and Vientiane High school Chanthabouly District Vientiane Capittal, Lao PDR including doing PR of the activities, 2) students recruitment to participate in online projects, 3) orientation for students and teachers online, 4) online study, 5) online assessment prior participating the activities, 6) project topic selection, 7) team building, viii) project planning, and ix) project outline submission to the advisor.

2) Project Implementation Process: consists of 1) setting target and concerned issues of the project, 2) designing work plan, 3) creating and searching for knowledge, and iv) handing on the project.

3) Collaborative Learning Exchange Process: consists of 1) exchanging information among Thai and Lao PDR's 
students, 2) validity checking of the information, 3) validity checking of the report, and 4) Thai and Lao PDR's students and teachers sharing opinions and supervising the project.

4) Project Presentation Process: consists of 1) presenting project outcomes by using augmented reality on m-learning technology with English and another ASEAN language; Thai students presents with English and Laos while Lao students presents with English and Thai, 2) providing feedback in order to improve project, and 3) giving compliment and rewards.

5) Evaluation Process: consists of 1) work piece evaluation, 2) students' performance evaluation, and 3) students' satisfaction assessment towards the model.

The model connects all relative components and processes of this learning model as illustrated in Fig. 1.

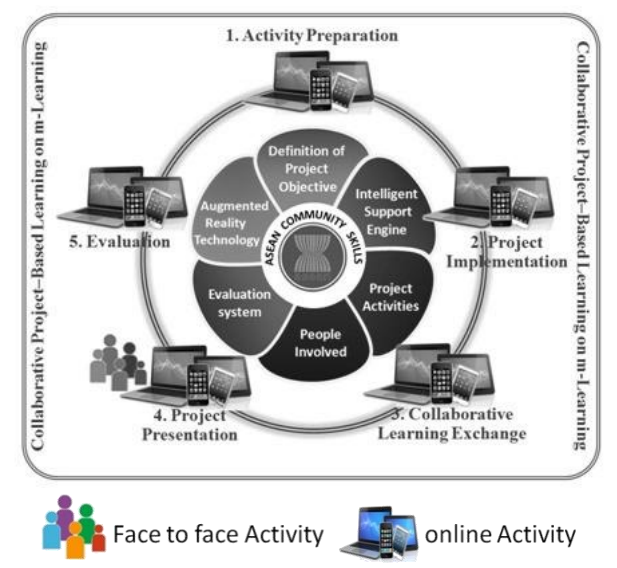

Fig. 1. Collaborative project-based learning via augmented reality on m-learning model to enhance basic ASEAN community skills for Thai students and the Lao People's Democratic Republic students.

\section{B. Assessment Outcomes of a Collaborative}

Project-Based Learning via Augmented Reality on m-Learning Model

TABLE I: COMPONENTS AND PROCESSES OF THE MODEL

\begin{tabular}{llll}
\hline \hline \multicolumn{1}{c}{ Details of Evaluation List } & \multicolumn{2}{c}{ Result } & \\
\cline { 2 - 3 } & $\bar{X}$ & S.D & Rating \\
\hline Components of the model & & & \\
1. Definition of Project Objective & 5.00 & 0.00 & highest \\
2. intelligent support engine & 5.00 & 0.00 & highest \\
3. Project Activities & 5.00 & 0.00 & highest \\
4. People Involved & 4.80 & 0.18 & highest \\
5. Evaluation system & 4.88 & 0.16 & highest \\
6. Augmented Reality technology. & 5.00 & 0.00 & highest \\
\hline \multicolumn{1}{c}{ Overview } & 4.95 & 0.05 & highest \\
\hline Processes of the model & & & \\
1. activity preparation & 5.00 & 0.00 & highest \\
2. operate the project & 5.00 & 0.00 & highest \\
3. sharing and collaborative learning & 5.00 & 0.00 & highest \\
between & & & \\
$\quad$ Thai students and The Lao People's & & & \\
$\quad$ Democratic Republic students by & & & \\
doing project & & & \\
4. presentation project & 4.93 & 0.15 & highest \\
5. evaluation & 4.93 & 0.15 & highest \\
\hline Overview & 4.97 & 0.06 & highest \\
\hline \hline
\end{tabular}

The collaborative project-based learning via augmented reality on m-learning model to enhance basic ASEAN community skills for Thai students and The Lao People's
Democratic Republic students evaluation assessed by five experts can be concluded as shown in Table I.

Evaluation of the model by five experts was evaluated at highest appropriateness, $(\bar{X}=4.96),($ S.D. $=0.05)$.

\section{DISCUSSION}

The creation of model had been sequentially processed. It starts from making analysis, synthesizing the collaborative learning concept, project-based learning concept, m-learning, and the use of augmented reality technology. Furthermore, it synthesizes the education philosophy and learning theory. The researcher then analyses and synthesizes Components and processes of the model along with performed in-depth interviews of five specialists; thereafter, modifies and adjusts the model upon those acquired recommendations from specialists

The model focuses on bringing all strategies of collaborative learning via m-learning and augmented reality technology by letting Thais and Laos students exchange knowledge, experiences, and opinions together. They cooperatively perform problem analysis through the learning process, connecting and reflecting their knowledge continuously. They also practice their English, Thai, and Lao language communication skill on the basis of current problems and situations validity. This induce to the creation of new knowledge derived from doing project via m-learning complying with the research of Berger [7] has studied on "Mobile Collaboration Tool for University Education" and identified that the use of personal digital assistants in Regensburg University is the supporting tools of both e-learning and m-learning, facilitates and fortifies a small group of collaborative learning. The students can share their knowledge among others and be able to access to knowledge resources through wireless network conveniently. Moreover, Hargis [8] found that the project-based learning is the instruction method that can link learners to the discovery and questions findings relating to students' interests. The designed model apply the augmented reality technology as a learning medium which can create better learning interests and the better learning. Consistently with the study of Malinka Ivanova and Georgi Ivanov [9], it reveals that augmented reality technology supports and enhances the learning.

\section{CONCLUSIONS}

1) Necessary components and processes of the model include six components and five processes.

The six components of the model were: 1) Definition of Project Objective, 2) Intelligent Support Engine, 3) Project Activities, 4) People Involved, 5) Evaluation system, and 6) Augmented Reality Technology.

The activities include with five processes were: 1) activity preparation, 2) project operation, 3) sharing and collaborative learning between Thai students and The Lao People's Democratic Republic students by doing project, 4) project presentation, and 5) evaluation

2) Evaluation result on model by five experts found that the model's components get the highest appropriateness with median score of 4.95 and with S.D. value of 0.05 . All the 
model processes get the highest appropriateness median score of 4.97 and with S.D. value of 0.06. In conclusion, the model gets the highest appropriateness with median score of 4.96 and with S.D. value of 0.05 .

\section{ACKNOWLEDGMENT}

The research work was supported by Department of Information and Communication Technology of Education, Faculty of Technical Education, King Mongkut's University of Technology North Bangkok, and Bodindecha (Sing Singhaseni) school, Bangkok, Thailand.

\section{REFERENCES}

[1] Collaborative Learning Management Guideline Towards ASEAN Community, Office of the Basic Education Commission, Ministry of Education, 2012.

[2] S. Phitsuwan, Meet Thai people, Leave Blank Gear to ASEA, Thairath, 2013, p. 15.

[3] Y. Puworawan, "Information technology systems that support and promote the alive library service," B.E. thesis, Chiang Mai Univ., Chiang Mai, Thailand, 2005.

[4] S. Distakul, "Collaborative learning," Kasetsart Educational Review, vol. 15 , no. $2,2000$.

[5] P. Wetulan. (August 2014). Mobile Learning (m-learning) through a wireless network. [Online]. Available: http://thaimlearning.blogspot.com/

[6] M. Dunleavy and C. Dede. (August 2014). Augmented reality teaching and learning. [Online]. pp. 1-31. Available: http://isites.harvard.edu/fs/docs/icb.topic1116077.files/DunleavyDed eARfinal.pdf

[7] S. Berger, R. Mohr, H. Nösekabel, and K. J. Schafer, "Mobile collaboration tool for university education," in Proc. IEEE WETICE 2003: Workshop on Enabling Technologies: Infrastructure for Collaborative Enterprises, June 2003, pp. 1080-1083.

[8] J. Hargis, "Collaboration, community and project-based learning Does it still work online?" International Journal of Instructional Media, vol. 32, no. 2, p. 157, March 2005.

[9] M. Ivanova and G. Ivanov, "Enhancement of learning and teaching in computer graphics through marker augmented reality technology," International Journal on New Computer Architectures and Their Applications (IJNCAA), vol. 1, no. 1, pp. 176-184, May 2011.

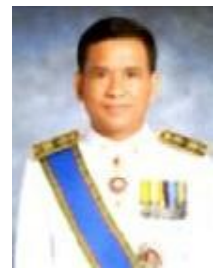

Wichai Trilek is studying for the doctor of philosophy in information and communication technology for education, Faculty of Technical Education, King Mongkut's University of Technology North Bangkok, Thailand. He obtained the education certificate, from Faculty of Education, Chandrakasem Rajabhat University, Bangkok, Thailand in 1977, high education certificate, from Faculty of Education, Phranakhon
Rajabhat University, Bangkok, Thailand in 1980, the bachelor's degree in secondary education, from Faculty of Education, Sukhothai Thammathirat Open University, Bangkok, Thailand in 1982, and received the master's degree in educational administration, from Faculty of Education, Ramkhamhaeng University, Bangkok, Thailand in 1999. He is currently an specialist teacher in computer and technology at Bodindecha (Sing Singhaseni) School, Bangkok, Thailand.

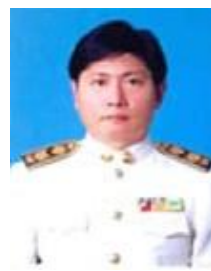

Pallop Piriyasurawong is an assistant professor at Division of Information and Communication Technology for Education, Faculty of Technical Education, King Mongkut's University of Technology North Bangkok (KMUTNB), Thailand. He received the B.Ed. degree in education technology (honor degree). He obtained his M.Ed. degree in educational technology, and received the Ph.D. degree in education technology, Cert. in energy conservation, Japan. He is an executive director of Ph.D. Program in information and communication technology for education, and the master of Science Department of Information and Communications Technology for Education, Faculty of Technical Education, King Mongkut's University of Technology North Bangkok (KMUTNB), Thailand.

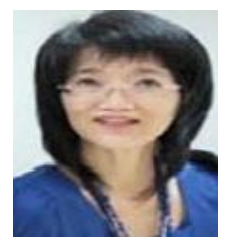

Namon Jeerungsuwan is currently a full time associate professor at the Department of Technological Education, Faculty of Technical Education, King Mongkut's University of Technology North Bangkok, Thailand. She has held a position of the director of Ph.D. Program in information and communication technology for education since 2011. She was the head of the Department of Educational Tech., KMUTNB, during 2002-2006. She received her doctoral degree in instructional design and development from University of South Alabama and her master's degree in educational media from Western Oregon University. She also received the award of the Royal Thai Government Scholarship and the award of Kappa Delta Phi during she was pursuing the doctoral degree in the USA. Her past experience included the director of Online Learning Center, KMUTNB. Currently, she is the executive committee of the e-Learning Association of Thailand, the Educational Technology Association of Thailand, and the Associate Editor of International Journal of Technology, Knowledge, and Society, and the member of IEEE society. 